International Intercalibration and

Intercomparison Measurements of Radon Progeny Particle Size Distribution

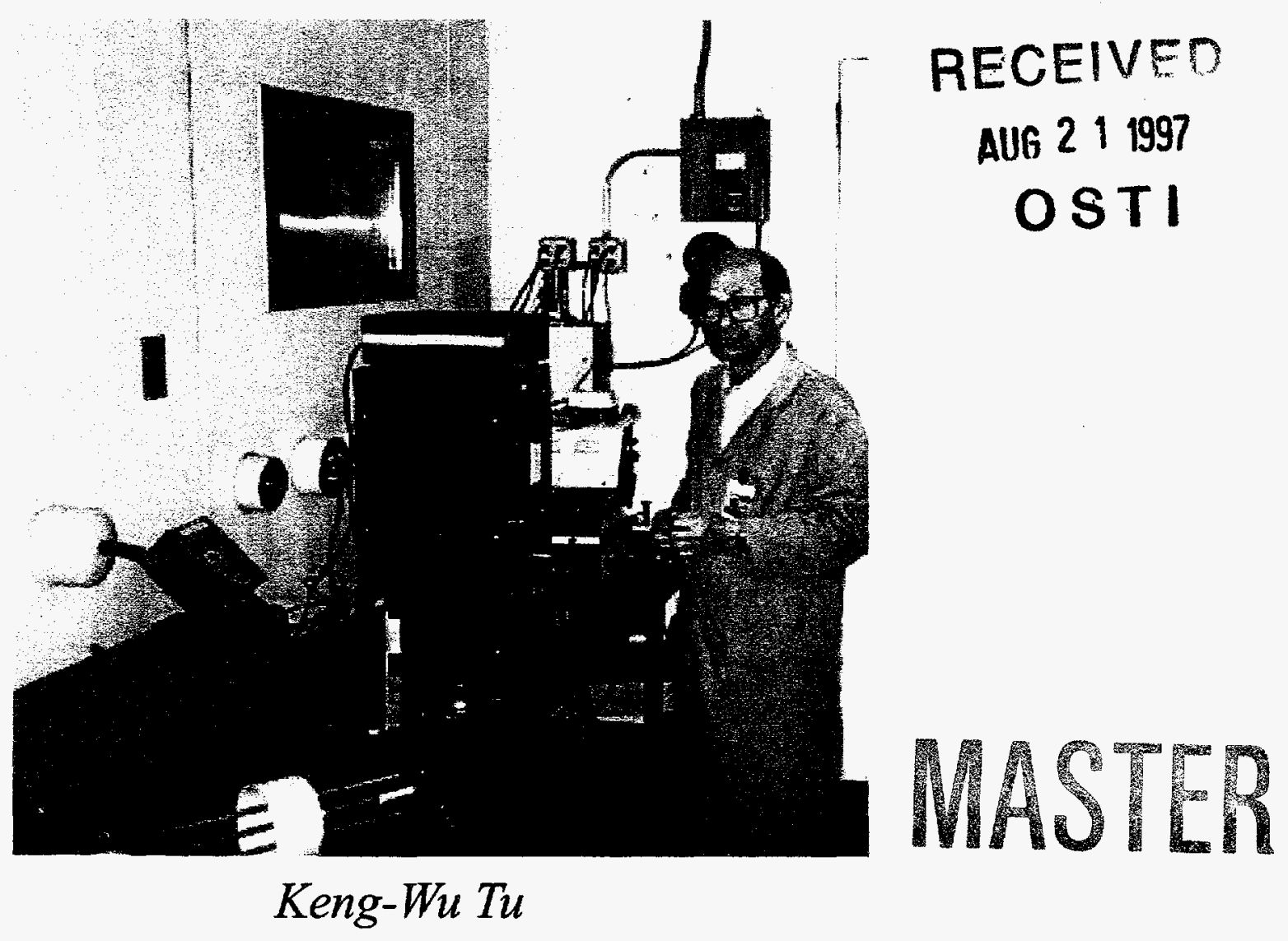

July 1997

DISTROUTON OF THS DOCUMENT IS UNMMTEO $)$ Y

201 Varick Street, 5th Floor, New York, NY 10014-4811 http://www.eml.doe.gov 


\title{
INTERNATIONAL INTERCALIBRATION AND INTERCOMPARISON Measurements of Radon Progeny Particle Size Distribution
}

\author{
Keng-Wu Tu \\ Environmental Measurements Laboratory \\ U.S. Department of Energy \\ 201 Varick Street, 5th Floor \\ New York, NY 10014-4811
}

July 1997

\section{DISCLAIMER}

"This report was prepared as an account of work sponsored by an agency of the United States Government. Neither the United States Government nor any agency thereof, nor any of their employees, makes any warranty, express or implied, or assumes any legal liability or responsibility for the accuracy, completeness, or usefulness of any information, apparatus, product, or process disclosed, or represents that its use would not infringe privately owned rights. Reference herein to any specific commercial product, process, or service by trade name, trademark, manufacturer, or otherwise, does not necessarily constitute or imply its endorsement, recommendation, or favoring by the United States Government or any agency thereof. The views and opinions of authors expressed herein do not necessarily state or reflect those of the United States Government or any agency thereof."

This report has been reproduced directly from the best available copy.

Available to DOE and DOE Contractors from the Office of Scientific and Technical Information, P. O. Box 62, Oak Ridge, TN 37831; prices available from (423) 576-8401.

Available to the public from the U.S. Department of Commerce, Technology Administration, National Technical Information Service, 5285 Port Royal Road, Springfield, Virginia 22161, (703) 487-4650. 


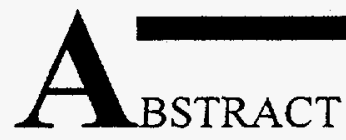

Because there is no standard method for ${ }^{222} \mathrm{Rn}$ progeny size measurements, verifying the performance of various measurement techniques is important. This report describes the results of an international intercomparison and calibration of ${ }^{222} \mathrm{Rn}$ progeny size measurements involving low pressure impactors (MOUDI and Berner) and diffusion battery systems, as well as both alpha- and gamma-counting methods. The intercomparison was held at the Environmental Measurements Laboratory from June 12-15, 1995. By using various measurement techniques and methods with different data analysis procedures, this intercomparison study allowed for a rigorous evaluation of instrument performance.

Five different well-controlled particle sizes $(80,90,165,395$, and $1200 \mathrm{~nm})$ of near monodisperse condensation Carnauba wax aerosol and two well-defined bimodal size spectra (160 and $365 \mathrm{~nm}$, and 70 and $400 \mathrm{~nm}$ ) were used. Twenty tests were completed, covering both low and high concentrations of ${ }^{222} \mathrm{Rn}$ and test aerosols. For the single-mode test aerosol, the measurements were found to agree within the size range covered by the test aerosols. The best agreement was found between the two low pressure impactors. Some differences between the impactor technique and the diffusion battery method were observed in the specific peak locations and the resultant geometric mean diameters. For the two bimodal size distribution aerosols, the MOUDI measurements showed two modes, while the other three devices showed a single mode size distribution. 

ABLE OF CONTENTS

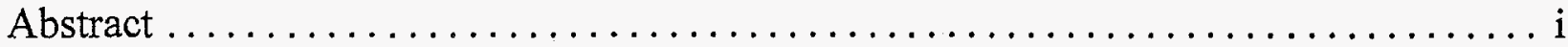

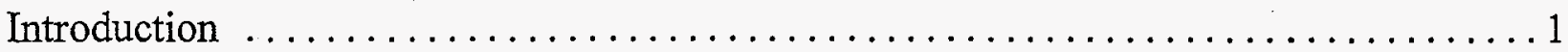

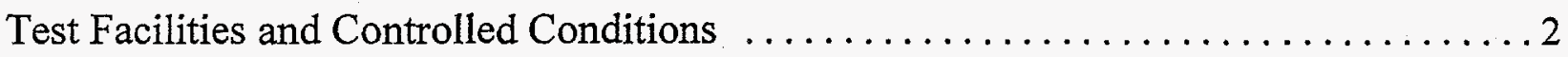

Measurement Systems and Size Unfolding Methods $\ldots \ldots \ldots \ldots \ldots \ldots \ldots \ldots \ldots$

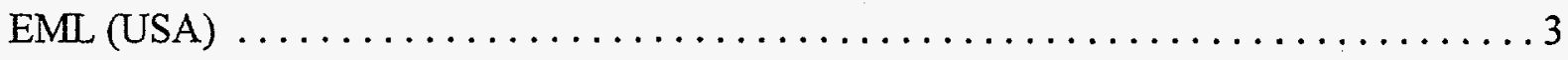

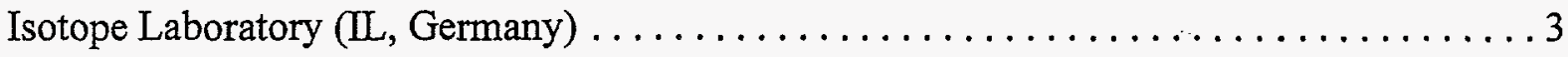

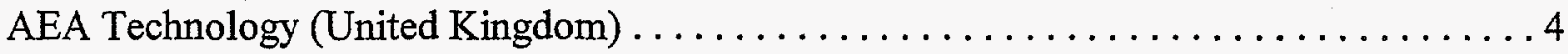

Australian Radiation Laboratory (ARL, Australia) $\ldots \ldots \ldots \ldots \ldots \ldots \ldots \ldots \ldots \ldots$

Wire Screen Diffusion Battery ............................. 5

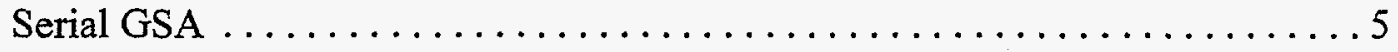

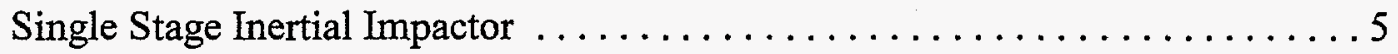

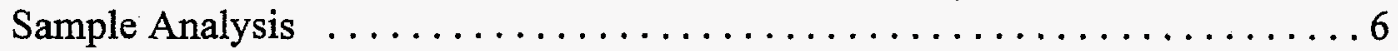

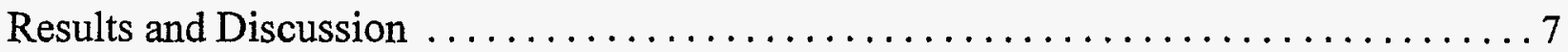

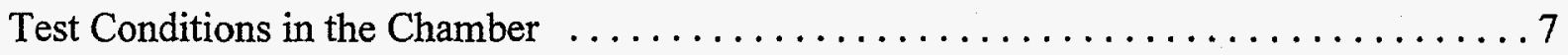

Aerosol Particle Size as Measured by Standard Aerosol Instruments . . . . . . . . . . . 7

Activity-Weighted Particle Size Distributions . ....................... 9

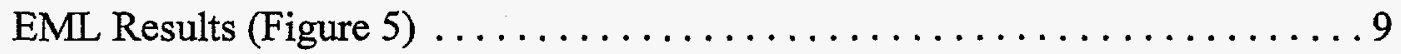

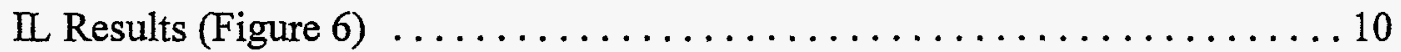

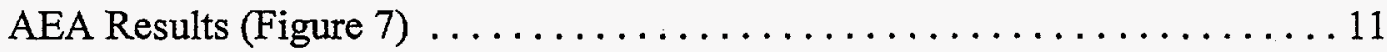

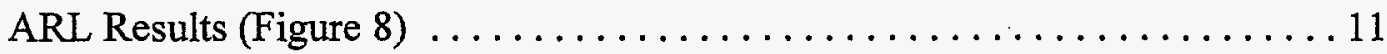

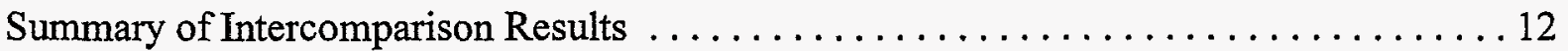

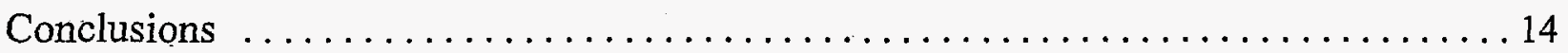

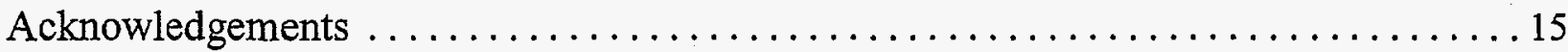

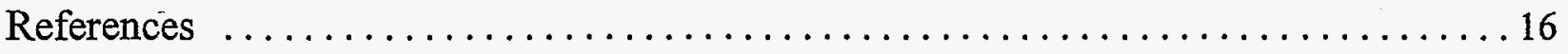

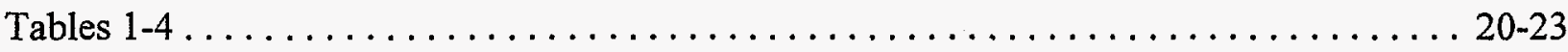

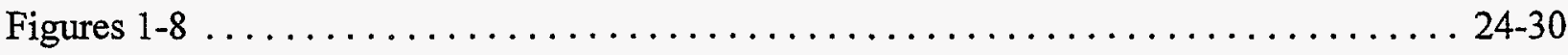

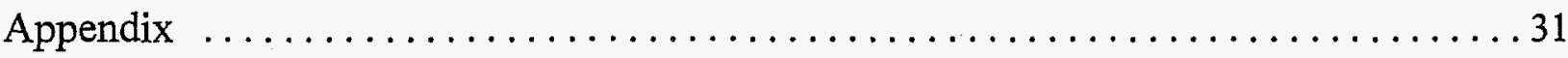

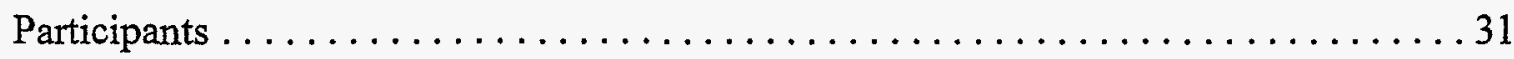





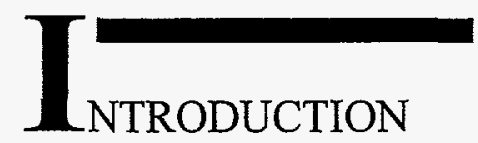

One of the major factors affecting the radiological health risk from ${ }^{222} \mathrm{Rn}$ in indoor and in mining environments is the size spectrum of particles associated with ${ }^{222} \mathrm{Rn}$ decay products. Many instruments and methods are commonly used for measuring ${ }^{222} \mathrm{Rn}$ progeny size distributions, and, therefore, confirming that these methods and instruments are reliable and accurate is important. Since there are no international or national standard methods presently available to assess ${ }^{222} \mathrm{Rn}$ progeny size distributions, it is necessary for laboratories involved in these measurements to participate in intercomparisons and calibrations.

In the past, diffusion battery systems of various designs were widely used to obtain activity size distribution measurements (Hopke et al. 1992; Tu and Knutson 1988; Knutson et al. 1988). Recent work has shown that the wide size range, low pressure impactors, such as the microorifice uniform deposit impactor (MOUDI), have some advantages over diffusion batteries for ${ }^{222} \mathrm{Rn}$ progeny size measurements (Tu et al. 1993; Knutson and Tu 1994; Reineking et al. 1994).

To investigate the comparability of these various size measurement methods and instruments that are based on different sampling mechanisms, an international intercalibration and intercomparison exercise was held at EML during the week of June 12-15, 1995. Seven groups, including both domestic and foreign laboratories, participated in this exercise. The experimental conditions in the EML test chamber (Chieco 1997) were well-controlled for ${ }^{222} \mathrm{Rn}$ and aerosol concentrations, temperature, relative humidity $(\mathrm{RH})$, and particularly for aerosol size distributions. Five near monodisperse aerosol particle sizes and two well-defined bimodal aerosol size distributions were generated to examine the accuracy and the reliability of each sizing technique.

This report summarizes and discusses the results of this intercomparison. The list of participants is given in the Appendix. Four of the participants provided data for this report: the AEA Technology (AEA, United Kingdom), the Isotope Laboratory of the University of Göttingen (IL, Germany), the Australian Radiation Laboratory (ARL, Australia), and the Environmental Measurements Laboratory (EML, USA). 


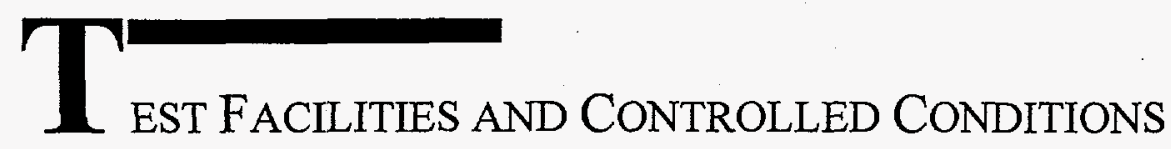

The tests for this intercomparison study were carried out in the EML $30 \mathrm{~m}^{3}$ test chamber. A description of the chamber, including chamber structure, ${ }^{222} \mathrm{Rn}$ gas and progeny monitoring systems, temperature, relative humidity, and quality assurance, is provided in the EML Procedures Manual, Section 6 (Chieco 1997). For this investigation, the chamber was equipped with the following instruments for generating aerosols, sampling and measurements:

1. Two TSI condensation aerosol generators (one with a high flow rate, up to $16 \mathrm{~L} \mathrm{~min} \mathrm{~m}^{-1}$, and

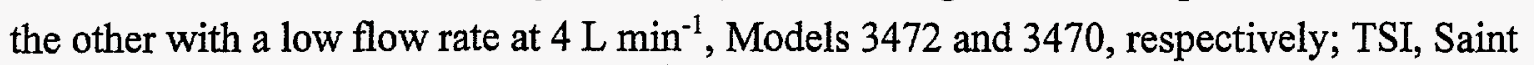
Paul, MN) that can produce either polydisperse or monodisperse aerosols of controlled sizes. [Refer to Tu (1994) for details about generation conditions and consequent particle sizes and concentrations.] Well-defined bimodal or even trimodal size distribution aerosols can be obtained by operating both instruments simultaneously, and by using controlled aerosol decay processes.

2. TSI scanning mobility particle sizer (SMPS), including condensation particle counter (Model 3025), mobility size analyzer (Model 3071A), SMPS software for PCs (TSI V1.1 for Model 390089), and a laser particle size spectrometer (Model Active Scattering Aerosol Spectrometer (ASASX); PMS, Inc., Boulder, CO). The SMPS and ASASX were used to monitor the aerosol size distributions and concentrations.

During the intercomparison test, ${ }^{222} \mathrm{Rn}$ concentrations were controlled at $\sim 1000$ and $\sim 2000$ $\mathrm{Bq} \mathrm{m} \mathrm{m}^{-3}$ levels. Temperature and $\mathrm{RH}$ in the chamber were maintained at $\sim 20^{\circ} \mathrm{C}$ and $\sim 40 \%$, respectively. Five controlled near-monodisperse condensation Carnauba wax aerosol particles, and two well-defined bimodal size distribution aerosols were produced for the intercomparison. 


\section{DISCLAMMER}

Portions of this document may be illegible in electronic image products. Images are produced from the best available original document. 



\title{
W Easurement Systems AND Size Unfolding MeTHods
}

\author{
EML (USA)
}

The sampling setup and the procedures used for these tests were similar to those used in the Twilight Mine study in Colorado in 1994 (Knutson and Tu 1996). The quality assurance steps for the sampling system and analysis process are described in the EML Procedures Manual, Section 2 (Chieco 1997). A MOUDI (MSP Corp., Minneapolis, MN) used in combination with a graded screen array (EMLGSA) (Holub and Knutson 1987; Knutson et al. in press) was modified to measure the expanded size range of 0.5 to $15000 \mathrm{~nm}$.

The EMLGSA consists of 60 and 100 mesh, stainless-steel screens having a 40-mm effective flow diameter. These screens are stacked in a 66-mm diameter single holder, with the 60-mesh screen upstream. Ten impaction stages and the corresponding cut-off diameters for the MOUDI are listed in Table 1. In this investigation, stages 3 to BB (see Table 1) were used to cover sizes up to $2000 \mathrm{~nm}$. The samples were taken simultaneously using the MOUDI, the EMLGSA and an open-faced filter. Sampling flow rates were $30 \mathrm{~L} \mathrm{~min}{ }^{-1}$ for the MOUDI, and $11 \mathrm{~L} \mathrm{~min}{ }^{-1}$ for both the EMLGSA and open-faced filter. After sampling, the front of each screen, the impaction plates, and the reference filter were simultaneously individually alpha-counted using 10 scintillation alpha-counters. The ${ }^{222} \mathrm{Rn}$ progeny activities were calculated using the RaabeWrenn (1969) least-squares method. A computer program based on an expectationmaximization algorithm (EM) (Maher and Laird 1985), modified by Knutson (1989), was used to calculate the particle size distributions from the activities measured on each of the MOUDI impaction plates and screens.

\section{ISOTOPE LABORATORY (IL, GERMANY)}

The size distributions of the aerosol-attached activities were measured with a low-pressure cascade impactor (BERNER, Model LP130), consisting of eight stages and a backup filter. This impactor operates at a flow rate of $1.8 \mathrm{~m}^{3} \mathrm{~h}^{-1}$. It was recalibrated in the diameter range of interest $(\mathrm{d}<1000 \mathrm{~nm}$ ) for absolute pressures of 190 and $300 \mathrm{mbar}$ behind the last stage. The efficiency curves of the impactor were determined with monodisperse, liquid aerosol particles (Sebacate, $\rho=0.9 \mathrm{~g} \mathrm{~cm}^{-3}$ ) produced by condensation processes using a Sinclair-LaMer type generator (Sinclair and LaMer 1949). After exiting the generator, the aerosols were passed through a differential mobility analyser (TSI, Model 3071), yielding monodisperse particles $\left(\sigma_{\mathrm{g}}<1.05\right)$ in the diameter range between 60 and $1500 \mathrm{~nm}$. In a decay volume, the monodisperse particles 
were tagged with the short-lived thoron decay product ${ }^{212} \mathrm{~Pb}$ (half-life $=10.6 \mathrm{~h}$ ). After sampling, the activities on the different impactor stages were measured by $\gamma$-spectroscopy. The $50 \%$ cutoff diameters of the five stages were 60 or $82,150,292,589$, and $1136 \mathrm{~nm}$. (The impaction efficiency on the last impactor stage can be changed from 60 and $82 \mathrm{~nm}$ by adjusting the pressure behind the last stage from 190 to 330 mbar.) Experimental results and theoretical calculations show that in the critical air flow range this pressure change has only a minor effect on the deposition characteristics of the preceding stages (Kesten et al. 1993). Calibration measurements in the larger diameter range between 1 and $10 \mu \mathrm{m}$ were performed using an optical method and showed $50 \%$ cut-off values of 2356,4242 and $8082 \mathrm{~nm}$ for stages 1,2 and 3, respectively (Gebhart and Roth 1974; Reineking et al. 1986).

During this intercomparison, measurements of the size fractionated activities of ${ }^{214} \mathrm{~Pb}$ on the eight impactor stages deposited on thin aluminum foils and the backup filter were measured after sampling. A well-type NaI gamma spectrometer in connection with the multichannel analyser was used for these measurements. The activity size distributions (approximated by a sum of lognormal distributions) were obtained from the measured size fractionated activities by comparing the measured values with simulated ones using two different optimization procedures: the Simplex method and the EM algorithm (Nelder and Mead 1965; Maher and Laird 1985).

\section{AEA TECHNOLOGY (UNTTED KINGDOM)}

A parallel channel diffusion battery (PCDB) was used to measure activity-size distributions. This instrument consisted of five parallel channels, each containing a removable glass fibre filter (Grade GFA, Whatman, U.K.), preceded by a different number of wire screens. Stainless-steel screen discs were loaded into each channel as follows: 1 x 100 mesh, 1 × 400 mesh, $4 \times 400$ mesh, $14 \times 400$ mesh, and $45 \times 400$ mesh. A sixth channel had no preceding screens and collected the total aerosol. Airflow, nominally $6.5 \mathrm{~L} \mathrm{~min}^{-1}$, through each channel was controlled by separate critical orifices mounted in the filter holders. Before each sample, and after the filters had been reloaded, the flow rate through each channel was measured with an electronic bubble flowmeter (Gilian Instrument Corp., NJ, U.S.A.).

After sampling, the filters were removed and transferred to gross alpha counters that had been previously calibrated for $20 \mathrm{~mm}$ diameter samples, having a counting geometry similar to the active area on the filters. Alpha count data were collected during 1-min periods for $30 \mathrm{~min}$. The individual ${ }^{222} \mathrm{Rn}$ progeny concentrations penetrating each channel were then calculated using a weighted least squares technique (Raabe and Wrenn 1969; Knutson 1989). 
Activity size distributions for the individual ${ }^{222} \mathrm{Rn}$ progeny and the potential alpha energy concentration (PAEC) were estimated from the penetration data using an EM algorithm (Maher and Laird 1985). The theoretical penetrations also required by the algorithm were calculated from the air flow through each channel and the physical dimensions of the screens (Cheng et al. 1985; Cheng and Yeh 1980; Ramumurthi and Hopke 1989).

\section{AUSTRALIAN RADIATION LABORATORY (ARL, AUSTRALIA)}

The system used by ARL for the sizing of ${ }^{222} \mathrm{Rn}$ progeny is a combined four-stage serial GSA (ARGSA) and a four-stage parallel wire screen diffusion battery (PDB), with a single stage inertial impactor $(\mathrm{CD})$. The alpha activity collected by each stage was determined using either alpha spectroscopic analyses for the ARGSA and the PDB, or by three count gross alpha analyses for the CI. The details of the ARL system are as follows.

\section{Wire Screen Diffusion Battery}

The PDB used four ARL sampling assemblies with in situ alpha counting, one of which is shown in Figure 1. Stages 1 and 2 used 10 and 34, respectively, of $3.7 \mathrm{~cm}$ diameter 105 woven mesh screens. Stage 3 used 30 sets of $9.5 \mathrm{~cm}$ diameter 105 woven mesh screens, and Stage 4 used 30 sets of $22.5 \mathrm{~cm}$ diameter 100 mesh screens. A single carbon vane pump was connected to a manifold containing four critical orifices. The exact flow rate for each stage was determined before the EML exercise using a calibrated bubble tube connected to the front of each sampling assembly. The wire screen collection efficiencies were derived as a function of particle size using the fan model theory (Cheng et al. 1980), including terms for impaction and interception of aerosols, as well as for diffusional collection.

\section{Serial GSA}

The ARGSA consisted of an open-faced filter holder, containing 105, 200, and 400 woven mesh screens, and a backup filter, as shown in Figure 2. Samples were collected at a sampling rate of $9.5 \pm 0.1 \mathrm{~min}^{-1}$ using a carbon vane pump. The wire screen collection efficiencies were derived as a function of particle size (Cheng et al. 1980), with corrections for internal losses in the screens and for the front-to-total ratio (Solomon and Ren 1992).

\section{Single Stage Inertial Impactor}

A singe stage inertial impactor was designed and built at ARL using the design methods outlined by Marple and Rubow (1986). The airborne radioactivity with diameters above the 
particle size cut-off is deposited directly onto a thin, aluminized Mylar window on the front of a solid-state alpha particle detector. At a total flow rate of $5.4 \mathrm{~L} \mathrm{~min}^{-1}\left(1.08 \mathrm{~L} \mathrm{~min}{ }^{-1}\right.$ through each of five, $0.075 \mathrm{~cm}$ diameter holes), the calculated $50 \%$ cut-off diameter was $770 \mathrm{~nm}$, with a Reynolds number of 2030 . The collection efficiency particle size response was fitted to a continuous function centered on the $50 \%$ cut-off point.

\section{Sample Analysis}

Sampling with the ARGSA, PDB, and CI was concurrently carried out at the end of a 15-min sampling period. The screens and filters from the ARGSA were transferred to four drawer assemblies. The four analog signals from these systems were multiplexed with the four analog signals from the PDB sampling heads for input to a single PC-based multichannel analyser. All eight stages were analyzed concurrently using a two-count alpha spectroscopy method to derive the activity concentration of ${ }^{218} \mathrm{Po},{ }^{214} \mathrm{~Pb},{ }^{214} \mathrm{Bi}$, and the PAEC for each stage. The alpha activity from the $\mathrm{CI}$ system was analyzed using a three-alpha count protocol to derive the activity concentration of ${ }^{218} \mathrm{Po},{ }^{214} \mathrm{~Pb},{ }^{214} \mathrm{Bi}$, and the PAEC collected by the impactor.

The activity concentrations for all stages were in turn analyzed using both the Twomey (1975) and EM algorithms to provide two sets of particle size distributions for each progeny, and for the PAEC over the size range of $0.5 \mathrm{~nm}$ to $3358 \mathrm{~nm}$. 


\section{$\mathbf{R}_{\text {esults and Discussion }}$}

\section{TEST CONDITIONS IN THE CHAMBER}

Table 2 gives the chamber conditions for the 20 sampling periods that were made available to participants during the intercomparison. As will be explained, seven different test aerosol conditions were presented, with three consecutive sampling periods for each of the first six conditions and two for the seventh condition.

As seen in Table 2, the sampling periods for each aerosol condition were spaced about $1 \mathrm{~h}$ apart. Aerosol conditions were changed at midday and overnight. For the midday change, about $2 \mathrm{~h}$ were allowed for the change to become complete.

As also seen in Table 2, conditions could not be kept steady within each group of three sampling tests. Typically, the radon concentration dropped from the first to the third sampling period. (The traffic in and out of the chamber evidently overwhelmed the radon control system.) The aerosol concentration typically increased modestly within each group of three sampling periods.

The decay product activity concentrations reported in Table 2 are taken from the hostlaboratory filter sample. These concentrations depend on both aerosol and radon concentrations. In many cases, the effects of increasing aerosol and decreasing radon roughly canceled each other, so that the decay product concentrations were nearly steady. The uncertainty of the ${ }^{218} \mathrm{Po}$ measurement was typically $10 \%$, and that for ${ }^{214} \mathrm{~Pb}$ was typically $3 \%$.

\section{AERosol Particle Size as MeASURED by StandARd AEROSOl INSTRUMENTS}

The most important parameter for this intercomparison was the particle size distribution of the test aerosols. Besides the many samples taken by the participants, samples were taken with two conventional aerosol measurement systems, the TSI SMPS and the PMS ASASX. The SMPS covers the size range from 10 to $800 \mathrm{~nm}$, while the ASASX covers the range 100 to 3000 $\mathrm{nm}$. Both instruments yield number-weighted size distributions rather than activity-weighted size distributions. However, an approximate conversion to the activity-weighted distribution was made by multiplying by the attachment rate coefficient (Porstendörfer et al., 1979).

Figures 3 and 4 show representative size distributions from the above two systems. Figure 3, SMPS, covers aerosol conditions 1 to 6 (condition 7 was outside the capability of the SMPS). 
Figure 4, ASASX, covers aerosol conditions 2 to 7 (condition 1 was outside the capability of the ASASX). Both number weighted and attachment rate weighted distributions are shown. All plots are presented in a normalized form, so that the area under each curve is unity. Keep in mind that the two different weightings are two representations of the same data.

Plot 1 in Figure 3 is the most complicated of all these plots, so we will discuss it in some detail. As indicated in the legend, this spectrum was taken at 14:16 on June 12 th, about $30 \mathrm{~min}$ before the first sampling period in Table 1. The attachment rate distribution shows a peak at a particle size of about $80 \mathrm{~nm}$, as well two other peaks above $200 \mathrm{~nm}$. The peak at $80 \mathrm{~nm}$ is from the generated wax aerosol, whereas the other peaks are from larger stray particles that were present in the chamber. (These particles may have entered the chamber while the participants carried apparatus in during the morning.) It is also seen that the peak at $80 \mathrm{~nm}$ is quite broad; generating a narrow distribution of particles of this small size is difficult.

Plots 2 to 4 of Figure 3 show distributions from aerosol conditions 2 to 4 . As intended, these were unimodal distributions. All of the distributions are narrow, consequently, the attachment rate weighted distributions are nearly the same as the number weighted distributions.

Plots 5 to 6 in Figure 3 show the bimodal distributions produced by operating the two aerosol generators simultaneously; they were set to produce two different sizes. Plot 5 is an especially good example of a high-quality bimodal test aerosol. The number weighted and attachment rate weighted forms of the distribution are quite different from each other because attachment weights are higher in large particles than in small ones.

The corresponding plots based on data from the ASASX are shown in Figure 4, which covers aerosol conditions 2 to 7 . As indicated in the plot legends, these data were usually taken within a few minutes of the SMPS data, but in one case there was an hour in between. In the first plot (aerosol condition 2), the particle size was near the lower limit of the ASASX, so only one side of the peak was detected.

The distributions in Figure 4 are systematically different from those in Figure 3 - the peaks are narrower and are found at a smaller size. In other words, these two instruments designed to measure the same parameter, but that are based on two different physical principles, gave different results. This is a common experience in aerosol measurements. It is our opinion that the SMPS is more accurate for sizes below $150 \mathrm{~nm}$, while the ASASX is more accurate for the larger particles. 
Later in this report, we will compare the SMPS and ASASX results with those from the measurements of the activity-weighted particle size.

\section{ACTIVITY-WEIGHTED PARTICLE SIZE DistrIBUTIONS}

In this section, we will discuss the results reported by the participants, namely, the activityweighted size distributions. First, we will present and discuss the results individually by participant. A summary comparison table will be given later.

As stated before, there is no widely-accepted standard method for measuring the activityweighted particle size of radon decay products. If different methods give different results, we are not able to state which is correct. However, if different methods give similar results, it enhances the probability that both methods are correct. If two methods differ in a systematic way, this can be kept in mind when comparing field data obtained by the two methods.

\section{EML Results (Figure 5)}

Figure 5 shows the complete set of results obtained by the host laboratory. These data were obtained using a system that covered the size range 0.5 to $2000 \mathrm{~nm}$. Each plot in Figure 5 gives four curves, one each for ${ }^{218} \mathrm{Po},{ }^{214} \mathrm{~Pb},{ }^{214} \mathrm{Bi}$, and the PAEC. Each curve has been normalized, so that the area under the curve is unity. Sample No. 4 failed, so that a plot is missing in Figure 5.

The first plot in Figure 5 is the most complicated, so we will discuss it in some detail. Three peaks or modes are seen in the figure. The peak near $1 \mathrm{~nm}$ consists of unattached decay products. For ${ }^{218} \mathrm{Po}$, this peak appears to contain about $30 \%$ of the total activity, while the peaks for ${ }^{214} \mathrm{~Pb}$ and ${ }^{214} \mathrm{Bi}$ are much smaller. Unattached decay products are present whenever the aerosol concentration is low, and when the aerosol particles are small. The difference in unattached fractions for the three decay product nuclides is commonly found, and is predictable from their half-lifes.

The second peak in plot 1 , at $70 \mathrm{~nm}$, consists of the Carnauba wax test aerosol as generated for the intercomparison. It is seen that the peak is quite narrow and its location agrees quite well with that found by the SMPS (Figure 3).

The third peak in plot 1 , at $300 \mathrm{~nm}$, clearly corresponds to the background particles mentioned in connection with plot 1 of Figure 3. However, the two peaks shown in the Figure 3 are merged into one in Figure 5. 
Plots 2 and 3 of Figure 5 show results from the two additional samples taken under aerosol condition 1. There is a noticeable evolution in that the peak at $300 \mathrm{~nm}$ is becoming less prominent. Also, a rudimentary peak is seen in the range 1 to $10 \mathrm{~nm}$. Based on the few samples, we cannot be confident that this is a real peak rather than just a measurement artifact.

Plots 5 to 6,7 to 9 , and 10 to 12 in Figure 5 are samples from the next three test aerosols. These plots are all quite straightforward. Each plot is dominated by one narrow peak that is the same for all three decay products. The peak width is deceptively narrow because the plots have been presented in a common format with five decades on the particle size axis. The peak locations differ from those in Figures 3 and 4. We will look at this more carefully in Tables 3 and 4.

In plot 10 there is a clear peak at $100 \mathrm{~nm}$, besides the main peak at $400 \mathrm{~nm}$. We think this consists of residual particles from the previous day's test.

Plots 12 to 15 and 16 to 18 in Figure 5 show the MOUDI/GSA results for the two bimodal test aerosols. The two modes can be seen in each plot. They are especially clear in plots 13 to15, but less clear in plots 16 to 18 where the two peaks differ greatly in peak area.

Plots 19 and 20 show the results from the seventh aerosol condition - an unimodal test aerosol with a particle size of about $1 \mu \mathrm{m}$. A dominant peak is seen at $1 \mu \mathrm{m}$. The two smaller peaks are probably residual particles from the morning's samples.

\section{$\underline{\text { L Results (Figure 6) }}$}

These 20 plots show results only for ${ }^{214} \mathrm{~Pb}$, derived from the gamma counting done by $\mathrm{L}$. The sampling system used by the $\mathrm{IL}$ covered the size range of 50 to $5000 \mathrm{~nm}$, so no information is available for the unattached mode. Therefore, the size distributions are plotted with four decades on the particle size axis, rather than five as in Figure 5.

As seen Figure 6, the $\mathbb{I}$ found that most particle size distributions from the intercomparisons could be described adequately with a simple unimodal plot. With plot 1 , the peak is centered at $110 \mathrm{~nm}$. This is close to the value that would be obtained by combining peaks 2 and 3 in plot 1 of Figure 5. Similarly, plots 13 to 15 and 16 to 18 show single peaks with a location that compares well with the combined peaks from the corresponding plots in Figure 5. 
Plot 3 is unique in that it shows a small peak at $3 \mu \mathrm{m}$. This is not seen in Figure 5. Small peaks are also seen in plots 19 and 20 . It is likely that these peaks are the residual particles from the previous test.

\section{AEA Results (Figure 7)}

As already explained, these results were obtained using a one-of-a-kind screen type diffusion battery with no impactor stage.

Plots 1 and 3 of Figure 7 show two peaks. The peak at $1 \mathrm{~nm}$, which clearly consists of unattached decay products, is quite narrow. The other peak is more broad and may represent the combination of the generated wax aerosol and some larger contamination particles in the chamber.

The nature of the measured distributions seems different for the different test aerosols. Plots 4 to 6 (aerosol condition 2) are complicated, with one peak in the range of 1 to $10 \mathrm{~nm}$ and a broad peak found above $100 \mathrm{~nm}$. The size distributions seem different for each of the decayproduct nuclides. Plots 7 to 9 are simpler and more uniform across the nuclides. In Figure 7, the simplest plots are 10 to 12 . These plots show a single (or at least dominant) peak that is surprisingly narrow in view of the belief that diffusion batteries have poor size resolution.

Plots 12 to 15 and 16 to 18 correspond to the bimodal test aerosols. These generally have a single peak in the range $100-1000 \mathrm{~nm}$. The single peak is broad and could represent a combination of two peaks.

\section{ARL Results (Figure 8)}

As already explained, the sampling system here consisted of a serial GSA, a four-stage wire screen diffusion battery, and a single stage impactor. This is also a one-of-a-kind sampling system. The inclusion of an impactor stage, with the screen materials selected for the diffusion battery, permitted coverage of the size range from $0.5-3000 \mathrm{~nm}$.

As seen in Figure 8, the best results (in terms of simplicity and consistency) were those for aerosol condition 4, plots 10 to 12 . For this condition, the plots showed a single mode (or at least a dominant mode) at $400 \mathrm{~nm}$, and the size distribution was nearly the same for the three decay products. The result for aerosol condition 7 , plot 19 , was also straightforward with a single peak at about $1000 \mathrm{~nm}$. 


\section{SUMMARY OF INTERCOMPARISON RESULTS}

Tables 3 and 4 present a comparison of the results obtained by the different measurement methods. In both tables, the column $\mathrm{D}_{\mathrm{c}}$ gives the modal particle size as determined by one of the two conventional aerosol instruments. All those diameter values $<165 \mathrm{~nm}$ were taken from the SMPS, while those $165 \mathrm{~nm}$ or larger were from the ASASX.

The main point of Table 3 is the comparison of the particle size distributions reported by the participants, as weighted by ${ }^{214} \mathrm{~Pb}$. This weighting was selected for presentation because it was the only specie measured by all participants. For this comparison, the particle size distributions are represented in terms of the parameters AGMD (activity-weighted geometric mean diameter) and GSD (geometric standard deviation). Where more than one mode was detected, these two parameters were separately computed for each mode.

In Test 1 , the value of $D_{c}$ is taken from the SMPS and represents only the main (wax particle) peak, excluding the other peaks discussed in connection with Figure 3. Likewise, the parameter values in the EML column pertain only to the main peak. If this had been lumped together with the peak identified as background particles (discussed in connection with plot 1 of Figure 5), the combined AGMD would probably have been about $100 \mathrm{~nm}$. In the $\amalg$ measurement, the wax + background particles were represented as one peak with $\mathrm{AGMD}=93 \mathrm{~nm}$ and $\mathrm{GSD}=2.86$, as was already noted in connection with plot 1 of Figure 6 . The AEA measurement also detected only one peak for ${ }^{214} \mathrm{~Pb}$ with parameters as shown in the Table 3. ARL did not report measurement results for Test 1 .

The results from Tests 2-12 were straightforward because the Carnauba wax aerosol increasingly dominated over the background particles. The $D_{c}$ value for Tests 4 to 6 was taken from the SMPS, while for Tests 7-12 it was taken from the ASASX. Table 3 shows good agreement between the $D_{c}$ value and the values from the two impactor-based systems (EML and II). The results from the diffusion battery-based systems (AEA and ARL) are less consistent than the inpactor-based results.

Tests 13 to 15 and 16 to 18 involved bimodal test aerosols produced by operating the two aerosol generators simultaneously, but at different settings. In the $D_{c}$ column, the values $160 \mathrm{~nm}$ and $70 \mathrm{~nm}$ for the smaller-sized mode were taken from the SMPS, while the $365 \mathrm{~nm}$ and $400 \mathrm{~nm}$ values were from the ASASX. For these tests, the MOUDI/GSA apparatus detected two peaks, so each test is represented by two lines in Table 3 . With one exception (Test 14), the results from the other three measurement systems could be represented by a single peak, as shown in the 
table. For the larger-sized mode. the AGMD value derived from the MOUDU GSA agreed quite well with the corresponding $D_{c}$ value. The agreement was not as good for the smaller-sized mode. The $\mathbb{L}$ apparatus measured the mixed aerosol as a single mode, with an $A G M D$ value near that of the larger-sized mode. The AGMD values from the AEA apparatus were always larger than the larger $D_{c}$ value, while the $A R L$ values were scattered.

Tests 19 and 20 were done with a $1200 \mathrm{~nm}$ test aerosol. These tests were included to test instrument performance at a size that is unusually large in the context of radon decay products. The impactor samplers handled this challenge and the ARL system also did quite well.

It is of interest also to examine the pattern of values within the columns of Table 3 . For the EML system, many of the GSDs were in a narrow range of values, 1.3 to 1.4. These values probably correspond in some way to the spacing of the cut-off diameters of the MOUDI impactor (see Table 1). For the $\Pi$ system, the GSD was generally larger, although this is in part due to the use of a single mode to fit bimodal aerosols.

Regarding the AEA sampler, it can be seen in Table 3 that the AGMD values Tests 6 to 20 were all near $500 \mathrm{~nm}$, despite test aerosol. In effect, this is an upper limit for the size that can be measured by a screen-type diffusion battery.

Table 4 gives the AGMD and GSD values for the PAEC weighted size distributions. As is seen in the table, three of the participating laboratories reported these parameters. The most noteworthy point about these values is that, for a given sampling system there is close agreement with the corresponding values in Table 3. For example, with the EML system, there was close agreement between the two tables for all but one of the tests (the exception was test 2). 
An intercomparison of ${ }^{212} \mathrm{Rn}$ progeny size measurement methods was performed using controlled near-monodisperse Carnauba wax particles in the EML test chamber at given ${ }^{222} \mathrm{Rn}$ concentrations. For the single mode size distributions, the four different size measurement methods and two activity counting methods (alpha and gamma) generally agreed on the major part of the size spectrum within the size range of $<500 \mathrm{~nm}$. The best agreement was found between the two low pressure impactors, the MOUDI and the Berner impactor. Some disagreements observed on the specific peak location and shape are as follows:

1. The diffusion battery method measurements tended to result in larger sizes than the test aerosol size and those obtained from the impactors.

2. For the bimodal size distributions, in which the modal diameters differed by a factor of 2.3 and 6, respectively, the MOUDI was able to identify both peaks as given in the test aerosols, while the other three methods did not observe the minor modes of the bimodal size spectra. 


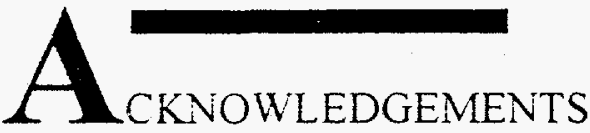

The authors wish to acknowledge the following: Kevin Clancy for arranging the transportation for the participants "instruments, Nancy Chieco for editing the manuscript, Bob Leifer and Ronald Knuth for their comments and suggestions. This study was sponsored by the Office of Health and Environmental Research (OHER), Office of Energy Research, U.S.

Department of Energy. 


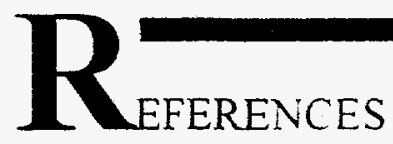

Cheng. Y. S. and H. S. Yeh

Theory of Screen Type Diffusion Battery

J. Aerosol Sci. 11:313 (1980)

Cheng, Y. S., H. C. Yeh and K. J. Brinsko

Use of Wire Screens as a Fan Model Filter

Aerosol Sci. Tech. 4:165 (1985)

Cheng, Y. S., J. A. Keating and G. M. Kanapilly

Theory and Calibration of Screen Type Diffusion Battery

J. Aerosol Sci. 11:549-556 (1980)

EML Procedures Manual

N. A. Chieco (Editor)

HASL-300, 28th Edition, Vol. 1, U. S. Department of Energy, New York, NY (1997)

Gebhart, J. and C. Roth

Particle Sizing by Means of Small Angle Scattering in the Light Beam of a Mercury Lamb Aerosol in Physik, Medizin und Technik, Proceedings of the Annual Meeting of the Association for Aerosol Research, Bad Soden, Germany, p. 41 (1974)

Holub, R. F. and E. O. Knutson

Measuring Polonium-218 Diffusion-Coefficient Spectra Using Multiple Wire-Screens in ${ }^{222} \mathrm{Rn}$ and Its Decay Products: Occurrence, Properties and Health Effects

ACS Symposium Series 331, American Chemical Society, Washington, D. C., pp. 340-356 (1987)

Hopke, P. K., R. Strydom, M. Ramamurthi, E. O. Knutson, K. W. Tu, P. Scofield, R. F. Holub, Y. S. Cheng, Y. F. Su, W. Winklmayr, J. C. Strong, S. Solomon and A. Reineking The Measurement of Activity-Weighted-Size Distributions of ${ }^{222} \mathrm{Rn}$ Progeny: Methods and Laboratory Intercomparison Studies

Health Physics 63:560-570 (1992) 
Knutson, E. O.

Personal Computer Programs for the Use in Radon/Thoron Progeny Measurements

USDOE Report EML-517, New York, NY (1989)

Knutson, E. O. and K. W. Tu

Intercomparison of Impactors and a Scanning Mobility Particle Sizer for Measuring ${ }^{222} \mathrm{Rn}$

Progeny Particle Size

USDOE Report EML-571, pp. 42-43, New York, NY (1994)

Knutson, E. O. and K. W. Tu

Size Distribution of Radon Progeny Aerosol in the Working Area of a Dry Former

Uranium Mine

Environment Int. 22:S617-S632 (1996)

Knutson, E. O., K. W. Tu, S. B. Solomon and J. Strong

Intercomparison of Three Diffusion Batteries for the Measurement 222Rn Decay Product Particle Size Distributions

Radiat. Protec. Dosim. 24:261-264 (1988)

Knutson, E. O., A. C. George, and K. W. Tu

The Graded Screen Technique for Measuring the Diffusion Coefficients of Radon

Decay Products

Aerosol Sci. Technol. (in press)

Kesten, J., G. Butterweck, J. Porstendörfer, A. Reineking and H. J. Heymel

An Online $\alpha$-Impactor for Short-lived ${ }^{222} \mathrm{Rn}$ Daughters

Aerosol Sci. Technol. 18:156-164 (1993)

Maher, E. F. and N. M. Laird

EM Algorithm Reconstruction of Particle Size Distributions from Diffusion Battery Data

J. Aerosol Sci. 16:557-570 (1985)

Marple, V. A. and K. L. Rubow

Theory and Design Guidelines

J. P. Lodge, Jr. and T. L. Chan (Editors)

Am. Ind. Hyg. Assoc., Akron, OH (1986) 
Nelder, J. and R. Mead

A Simplex Method for Function Minimisation

Comput. J. 7:308-313 (1965)

Porstendörfer, J., G. Robig and A. Ahmed

Experimental Determination of the Attachment Coefficients of Atoms and Ions on Monodisperse Aerosols

J. Aerosol Sci. 10:21-28 (1979)

Raabe, O. G. and M. E. Wrenn

Analysis of ${ }^{222} \mathrm{Rn}$ Daughter Samples by Weighted Least Squares

Health Phys. 17:593-605 (1969)

Ramamurthi, M. and P. K. Hopke

On Improving the Validity of Wire Screen "Unattached" Fraction Rn Daughter Measurements Health Phys. 56:189 (1989)

Reineking, A., J. Porsendörfer and K. H. Becker

Comparison Measurements of ${ }^{222} \mathrm{Rn}$ Daughter Activity Size Distributions with Cascade Impactors and High-Volume Screen Diffusion Batteries

In: AEROSOLS: Formation and Reactivity, Proceedings of 2nd International

Aerosol Conference, Berlin, Pergamon Press, NY, pp. 1158-1163 (1986)

Reineking A., E. O. Knutson, A. C. George, S. B. Solomon, J. Kesten, G. Butterweck and J. Porstendörfer

Size Distribution of Unattached and Aerosol-Attached Short-Lived ${ }^{222} \mathrm{Rn}$ Decay Products:

Some Results of Intercomparison Measurements

Radiat. Protec. Dosimetry 56:113-118 (1994)

Solomon, S. B. and T. Ren

Counting Efficiencies for Alpha Particles Emitted from Wire Screens

Aerosol Sci. Technol. 17:69-83 (1992)

Sinclair, D. and V. LaMer

Monodisperse Condensation Aerosol Generator

Chem. Rev. 44:245 (1949) 
Tu, K. W.

Aerosol Generation/Measurement Facility for EML's ${ }^{222} \mathrm{Rn}$ Chamber

USDOE Report EML-571, New York, NY, p. 45 (1994)

Tu, K. W. and E. O. Knutson

Indoor Radon Progeny Particle Size Distribution Measurements Made with Two Different Methods

Radiation Protec. Dosim. 24:251-255 (1988)

Tu, K. W., A. R. Hutter and P. Shebell

Indoor ${ }^{222} \mathrm{Rn}$ Progeny Size Measurements in Pennsylvania

USDOE Report EML-560, p. 23 (1993)

Tu. K. W., E. O. Knutson and A. C. George

Indoor ${ }^{222}$ Rn Progeny Aerosol Size Measurements in Urban, Suburban, and Rural Regions Aerosol Sci. Technol. 66:72-79 (1994)

Twomey, S.

Comparison of Constrained Linear Inversion and an Iterative Algorithm Applied to the Indirect Estimation of the Particle Size Distribution

J. Comp. Phys. 18:188-200 (1975) 


\section{TABLE 1}

IMPACTION STAGES AND THE CORRESPONDING CUT-OFF

DIAMETERS FOR THE MOUDI

\begin{tabular}{cc}
\hline Stage & $\begin{array}{c}\text { Cut-off diameter } \\
(\mathbf{n m})\end{array}$ \\
\hline Inlet & 15000 \\
1 & 10000 \\
2 & 5600 \\
3 & 3200 \\
4 & 1800 \\
5 & 1000 \\
6 & 560 \\
7 & 290 \\
8 & 173 \\
B & 97 \\
BB & 45 \\
\hline
\end{tabular}


TABLE 2

EXPERIMENTAL CONDITIONS IN THE CHAMBER AND THE TOTAL RADON PROGENY ACTIVITIES AND PAEC

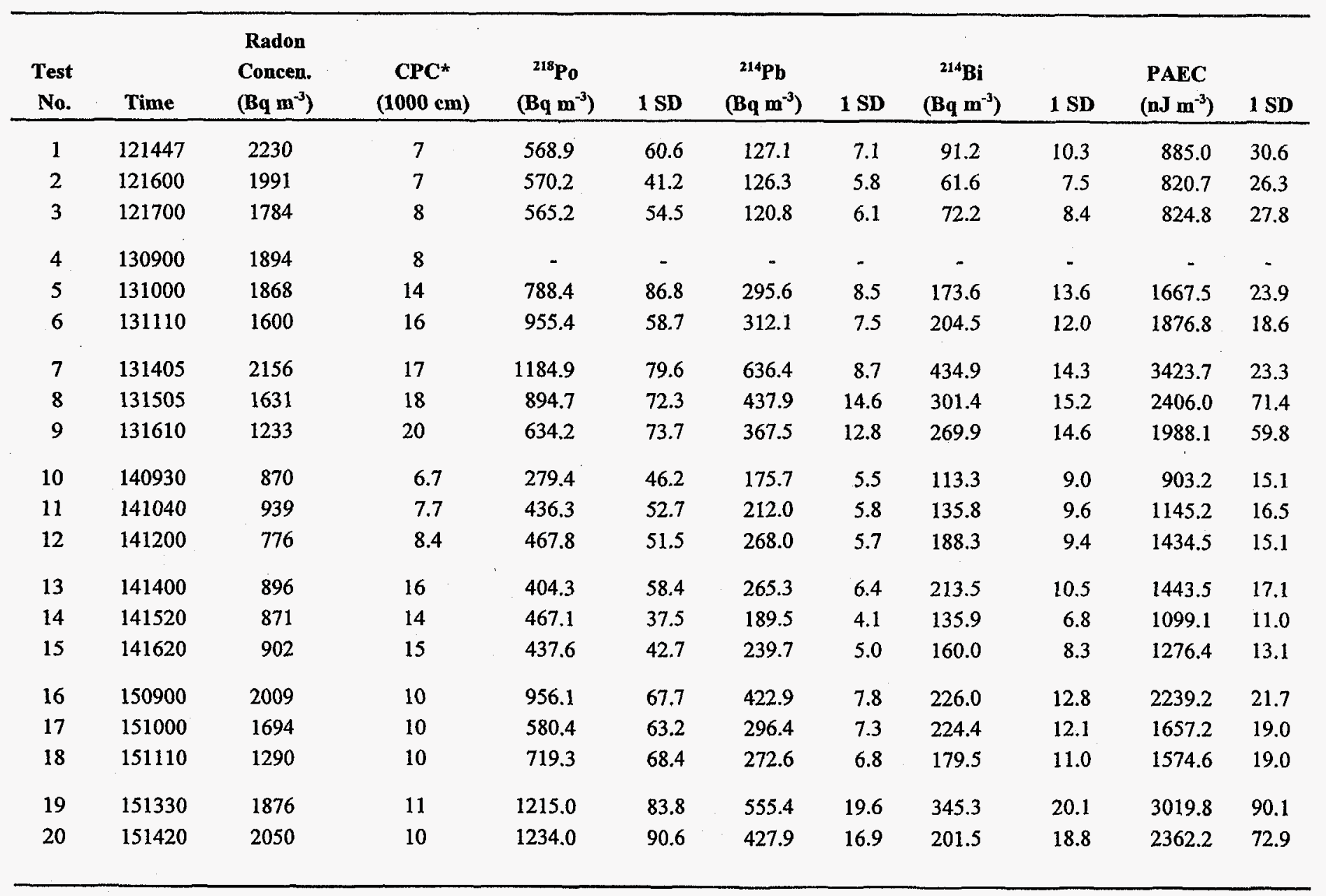

* Particle number concentration with TSI 3025 condensation particle counter. 
TABLE 3

COMPARISON OF ${ }^{214} \mathrm{~Pb}$ PARTICLE SIZE DISTRIBUTIONS FROM EML, MOUDI, $\Pi$, BERNER IMPACTOR, AND AEA AND ARL DIFUSION BATTERY SYSTEMS

\begin{tabular}{|c|c|c|c|c|c|c|c|c|c|c|}
\hline \multirow[b]{2}{*}{$\begin{array}{l}\text { Test } \\
\text { No. }\end{array}$} & \multirow[b]{2}{*}{ Time } & \multirow[b]{2}{*}{$\begin{array}{c}\mathrm{Dc^{* }} \\
(\mathbf{n m})\end{array}$} & \multicolumn{2}{|c|}{ EML } & \multicolumn{2}{|c|}{ IL } & \multicolumn{2}{|c|}{ AEA } & \multicolumn{2}{|c|}{ ARL } \\
\hline & & & $\begin{array}{c}\text { AGMD }+ \\
(\mathbf{n m})\end{array}$ & GSD $\$$ & $\begin{array}{c}\mathbf{A G M D} \dagger \\
(\mathbf{n m})\end{array}$ & GSD $\ddagger$ & $\underset{(\mathbf{n m})}{\operatorname{AGMD}} \boldsymbol{\phi}$ & GSD $\ddagger$ & $\underset{(\mathbf{n m})}{\mathbf{A G M D}+}$ & GSD $\ddagger$ \\
\hline 1 & 121447 & 80 & 56 & 1.58 & 93 & 2.86 & 69 & 1.98 & - & - \\
\hline 2 & 121600 & " & 67 & 2.67 & 163 & 2.62 & - & - & 100 & 1.43 \\
\hline 3 & 121700 & $"$ & 79 & 1.7 & 85 & 3.13 & - & - & 53 & 1.01 \\
\hline 4 & 130900 & 90 & - & - & 86 & 1.68 & 281 & 3.7 & 325 & 1.3 \\
\hline 5 & 131000 & " & 84 & 1.61 & 89 & 1.76 & 119 & 2.67 & 37 & 1.26 \\
\hline 6 & 131110 & $"$ & 84 & 1.6 & 92 & 1.64 & 635 & 7.58 & 101 & 1.28 \\
\hline 7 & 131405 & 165 & 174 & 1.37 & 172 & 1.54 & 446 & 3.43 & 339 & 1.29 \\
\hline 8 & 131505 & 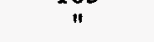 & 158 & 1.56 & 172 & 1.54 & 485 & 1.94 & 1588 & 1.64 \\
\hline 9 & 131610 & & 167 & 1.6 & 177 & 1.5 & 504 & 1.46 & 1070 & 1.43 \\
\hline 10 & 140930 & 395 & 374 & 1.31 & 356 & 1.89 & 504 & 1.27 & 339 & 1.29 \\
\hline 11 & 141040 & 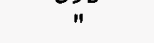 & 375 & 1.3 & 380 & 1.63 & 504 & 1.27 & 607 & 1.39 \\
\hline 12 & 141200 & $"$ & 393 & 1.34 & 395 & 1.90 & 494 & 1.59 & 768 & 1.28 \\
\hline \multirow[t]{2}{*}{13} & 141400 & $160 \&$ & 103 & 1.33 & - & - & - & - & - & - \\
\hline & & 365 & 375 & 1.32 & 291 & 2.17 & 480 & 1.87 & - & - \\
\hline \multirow{3}{*}{14} & & & & & & & & & & \\
\hline & 141520 & " & 104 & 1.36 & - & - & - & - & 150 & 1 \\
\hline & & & 374 & 1.34 & 344 & 1.63 & 451 & 2.23 & 275 & 1 \\
\hline \multirow[t]{2}{*}{15} & 141620 & $"$ & 83 & 1.78 & - & - & - & - & - & - \\
\hline & & & 374 & 1.35 & 289 & 1.88 & 497 & 1.51 & 233 & 1.38 \\
\hline \multirow[t]{2}{*}{16} & 150900 & & 95 & 1.38 & - & - & - & - & - & - \\
\hline & & $\begin{array}{c}400 \\
\text { (Bimodal) }\end{array}$ & 377 & 1.32 & 323 & 1.81 & 440 & 2.81 & 171 & 1.28 \\
\hline \multirow[t]{2}{*}{17} & 151000 & " & 110 & 1.33 & - & - & - & - & - & - \\
\hline & & & 386 & 1.37 & 421 & 1.85 & 502 & 1.45 & 264 & 1.61 \\
\hline \multirow[t]{2}{*}{18} & 151110 & $"$ & 100 & 1.34 & - & - & - & - & - & - \\
\hline & & & 375 & 1.32 & 383 & 1.74 & 505 & 1.38 & 489 & 1.64 \\
\hline 19 & 151330 & 1200 & 1277 & 1.32 & 1327 & 1.18 & - & - & 931 & 1.3 \\
\hline 20 & 151420 & RLO & 1187 & 1.41 & 1373 & 1.18 & - & - & - & - \\
\hline
\end{tabular}

* Test particle modal diameter.

$\uparrow$ Activity-weighted geometric mean diameter.

$\ddagger$ Geometric standard deviation. 
TABLE 4

COMPARISON OF PAEC PARTICLE SIZE DISTRIBUTIONS FROM THE EML MOUDI AND AEA AND ARL DIFFUSION BATTERY SYSTEMS

\begin{tabular}{|c|c|c|c|c|c|c|c|c|}
\hline \multirow[b]{2}{*}{$\begin{array}{l}\text { Test } \\
\text { No. }\end{array}$} & \multirow[b]{2}{*}{ Time } & \multirow[b]{2}{*}{$\begin{array}{l}D c^{*} \\
\text { (nm) }\end{array}$} & \multicolumn{2}{|c|}{ EML } & \multicolumn{2}{|c|}{$\mathbf{A E A}$} & \multicolumn{2}{|c|}{ ARL } \\
\hline & & & $\begin{array}{c}\mathrm{AGMD}^{\dagger} \\
(\mathbf{n m})\end{array}$ & GSD $\ddagger$ & $\begin{array}{c}\mathbf{A G M D}+ \\
\text { (nm) }\end{array}$ & GSD $\ddagger$ & $\begin{array}{c}\text { AGMD } \\
\text { (nm) }\end{array}$ & GSD! \\
\hline $\begin{array}{l}1 \\
2 \\
3\end{array}$ & $\begin{array}{l}121447 \\
121600 \\
121700\end{array}$ & $\begin{array}{l}80 \\
" \\
"\end{array}$ & $\begin{array}{r}59 \\
120 \\
79\end{array}$ & $\begin{array}{l}1.51 \\
1.51 \\
2.18\end{array}$ & $\begin{array}{c}77 \\
- \\
119\end{array}$ & $\begin{array}{c}1.66 \\
- \\
3.7\end{array}$ & $\begin{array}{r}- \\
160 \\
63\end{array}$ & $\begin{array}{l}- \\
2.25 \\
2.39\end{array}$ \\
\hline $\begin{array}{l}4 \\
5 \\
6\end{array}$ & $\begin{array}{l}130900 \\
131000 \\
131110\end{array}$ & $\begin{array}{c}90 \\
" \\
"\end{array}$ & $\begin{array}{l}- \\
84 \\
85\end{array}$ & $\begin{array}{l}- \\
1.6 \\
1.56\end{array}$ & $\begin{array}{l}192 \\
121 \\
208\end{array}$ & $\begin{array}{l}3.3 \\
2.33 \\
3.75\end{array}$ & $\begin{array}{l}154 \\
121 \\
117\end{array}$ & $\begin{array}{l}2.28 \\
2.1 \\
1.49\end{array}$ \\
\hline $\begin{array}{l}7 \\
8 \\
9\end{array}$ & $\begin{array}{l}131405 \\
131505 \\
131610\end{array}$ & $\begin{array}{c}165 \\
" \\
"\end{array}$ & $\begin{array}{l}173 \\
158 \\
165\end{array}$ & $\begin{array}{l}1.37 \\
1.58 \\
1.6\end{array}$ & $\begin{array}{l}465 \\
484 \\
492\end{array}$ & $\begin{array}{l}3.25 \\
2.43 \\
1.96\end{array}$ & $\begin{array}{l}413 \\
322 \\
249\end{array}$ & $\begin{array}{l}1.11 \\
2.53 \\
2.43\end{array}$ \\
\hline $\begin{array}{l}10 \\
11 \\
12\end{array}$ & $\begin{array}{l}140930 \\
141040 \\
141200\end{array}$ & $\begin{array}{c}395 \\
" \\
"\end{array}$ & $\begin{array}{l}374 \\
375 \\
395\end{array}$ & $\begin{array}{l}1.31 \\
1.3 \\
1.34\end{array}$ & $\begin{array}{l}504 \\
501 \\
502\end{array}$ & $\begin{array}{l}1.41 \\
1.46 \\
1.45\end{array}$ & $\begin{array}{l}413 \\
513 \\
484\end{array}$ & $\begin{array}{l}1.11 \\
1.36 \\
1.5\end{array}$ \\
\hline 13 & 141400 & $\begin{array}{l}160 \& 365 \\
\text { (Bimodal) }\end{array}$ & $\begin{array}{l}100 \\
377\end{array}$ & $\begin{array}{l}1.36 \\
1.32\end{array}$ & 485 & $\overline{1.81}$ & - & - \\
\hline 14 & 141520 & $"$ & $\begin{array}{l}103 \\
372\end{array}$ & $\begin{array}{l}1.37 \\
1.34\end{array}$ & 451 & 2.36 & 302 & $1 . \overline{75}$ \\
\hline 15 & 141620 & $"$ & $\begin{array}{r}82 \\
372\end{array}$ & $\begin{array}{l}1.86 \\
1.31\end{array}$ & - & $2 . \overline{2.04}$ & 320 & 1.07 \\
\hline 16 & 150900 & $\begin{array}{c}70 \& \\
400 \\
\text { (Bimodal) }\end{array}$ & $\begin{array}{r}92 \\
379\end{array}$ & $\begin{array}{l}1.41 \\
1.32\end{array}$ & - & $2 . \overline{28}$ & 325 & $\overline{1.65}$ \\
\hline 17 & 151000 & $"$ & $\begin{array}{l}109 \\
386\end{array}$ & $\begin{array}{l}1.33 \\
1.36\end{array}$ & $-\dot{493}$ & $\overline{166}$ & 542 & $2 . \overline{5}$ \\
\hline 18 & 151110 & $"$ & $\begin{array}{r}91 \\
376\end{array}$ & $\begin{array}{l}1.44 \\
1.3\end{array}$ & 500 & 1.51 & 640 & $\overline{1.93}$ \\
\hline $\begin{array}{l}19 \\
20\end{array}$ & $\begin{array}{l}151330 \\
151420\end{array}$ & 1200 & $\begin{array}{l}1200 \\
1180\end{array}$ & $\begin{array}{l}1.42 \\
1.41\end{array}$ & $\begin{array}{l}472 \\
466\end{array}$ & $\begin{array}{l}2.0 \\
2.12\end{array}$ & $\begin{array}{c}993 \\
-\end{array}$ & $\begin{array}{c}1.4 \\
-\end{array}$ \\
\hline
\end{tabular}

* Test particle modal diameter.

$\dagger$ Activity-weighted geometric mean diameter.

$\ddagger$ Geometric standard deviation. 


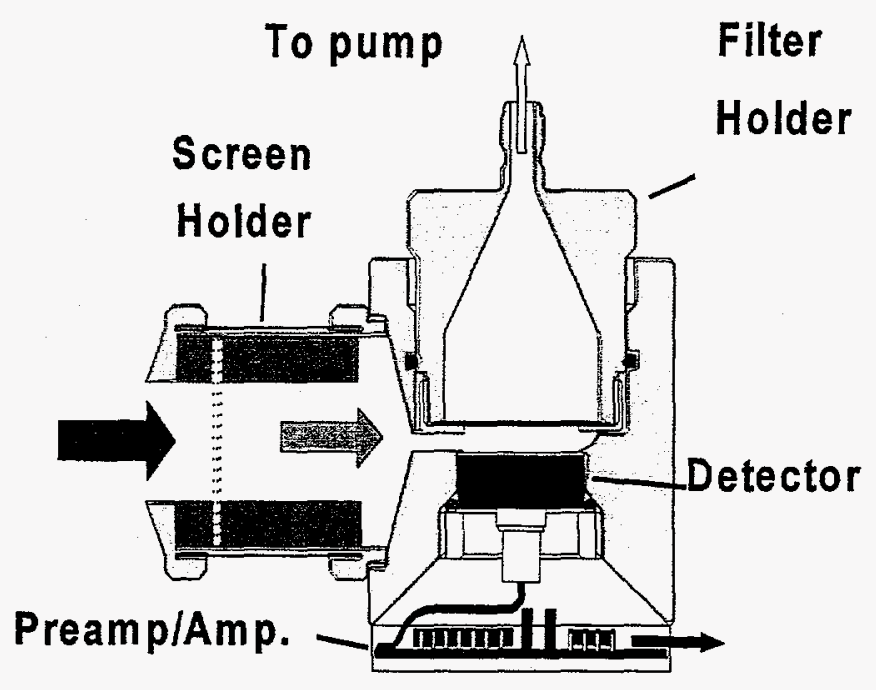

Figure 1. ARL sampling assembly for the diffusion battery.

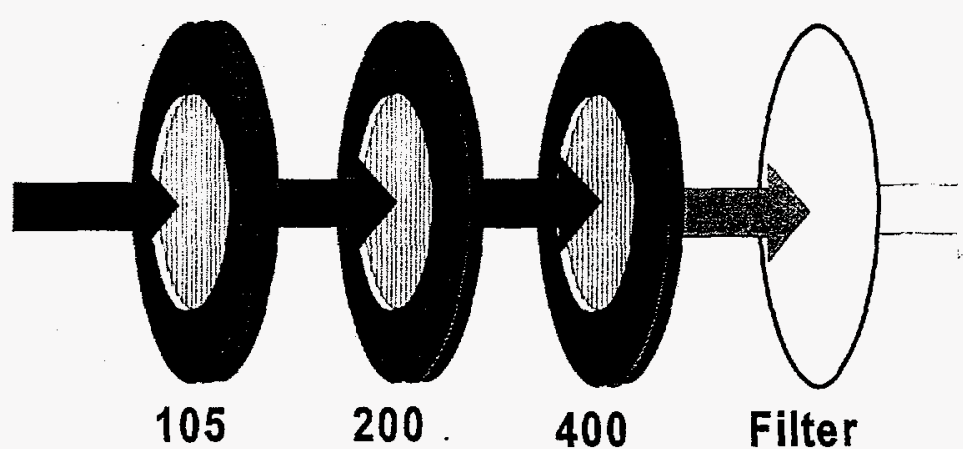

Figure 2. ARL serial graded screen array. 

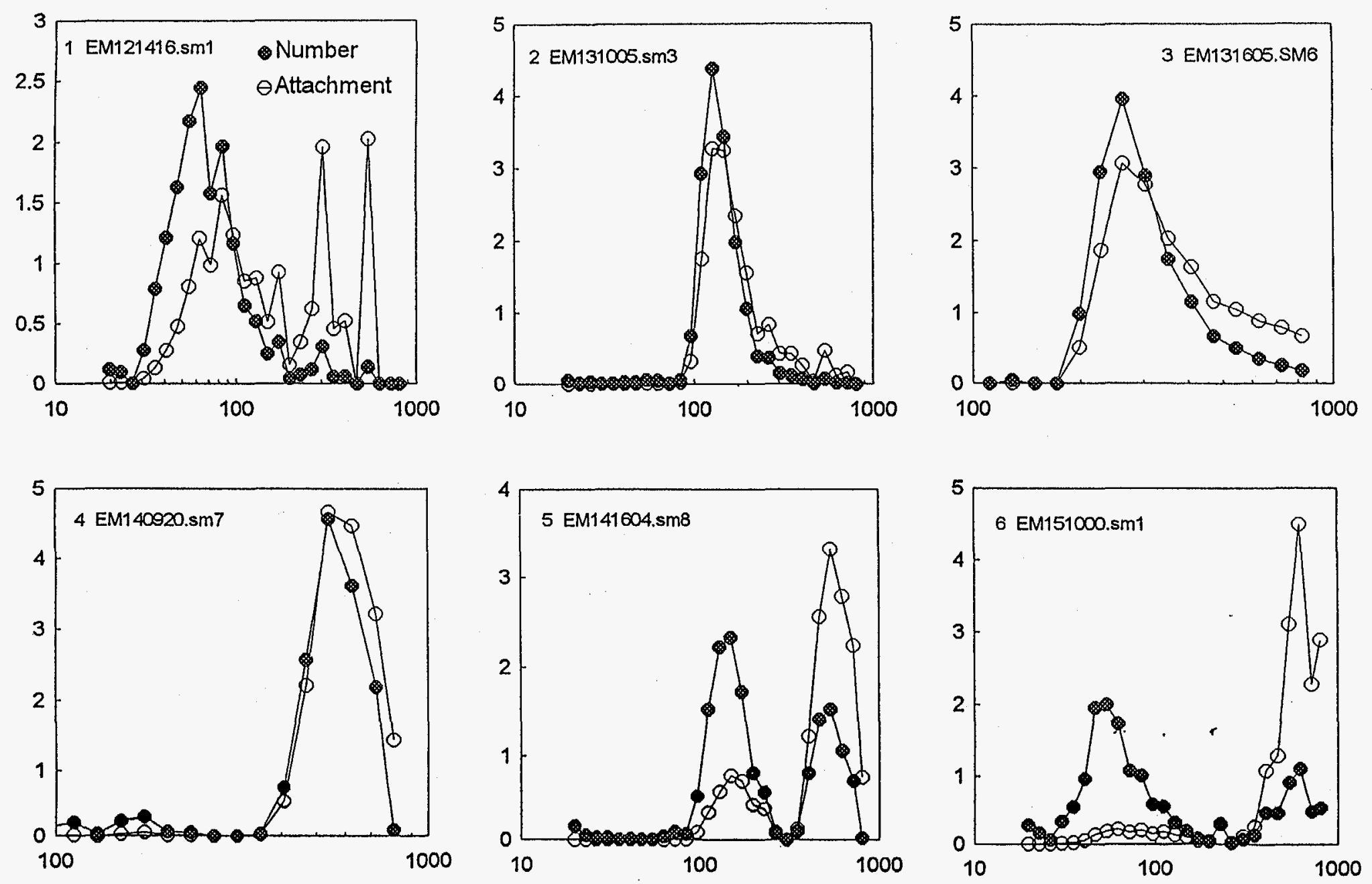

Figure 3. EML condensation Carnauba wax particle size distributions: number-weighted (dot) and attachment-rate-weighted (circle) measured with the SMPS. Conditions 1 to 4 , single mode; 5 and 6 , bimodal. $\mathrm{X}$-axis: diameter, $\mathrm{nm}$; $\mathrm{y}$-axis: $\mathrm{dX} / \mathrm{X}$ dlog $\mathrm{D}$, where $\mathrm{x}=$ number concentration $\left(\mathrm{cm}^{-3}\right)$ or attachment rate $\left(\mathrm{h}^{-1}\right)$. 

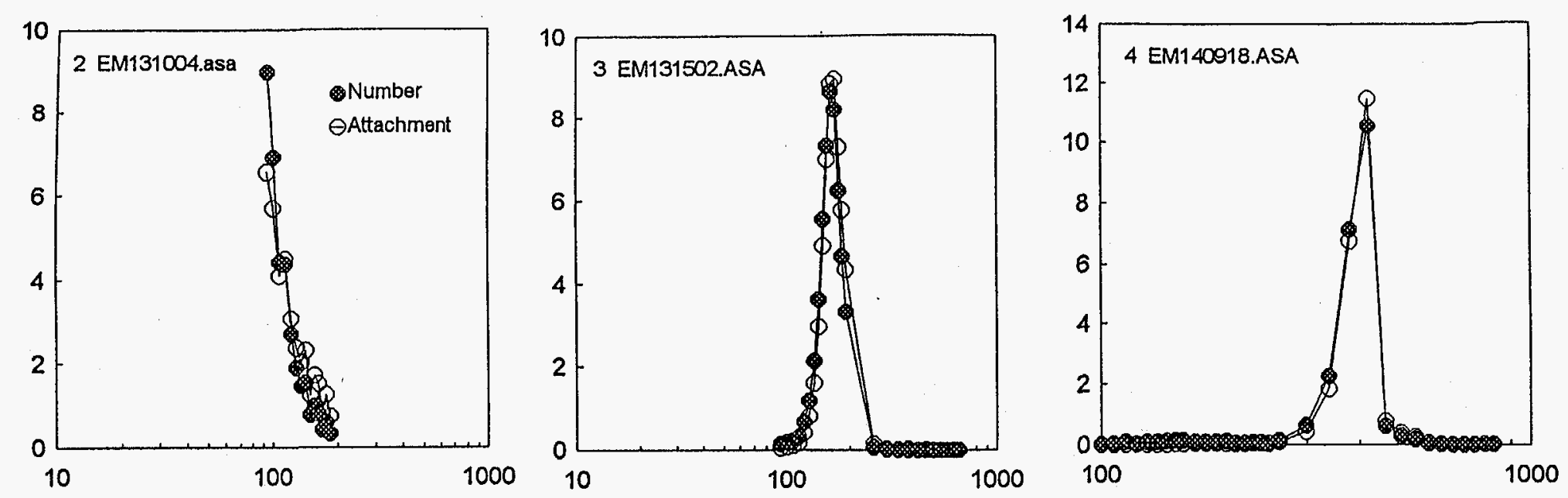

$\dot{\sim}$
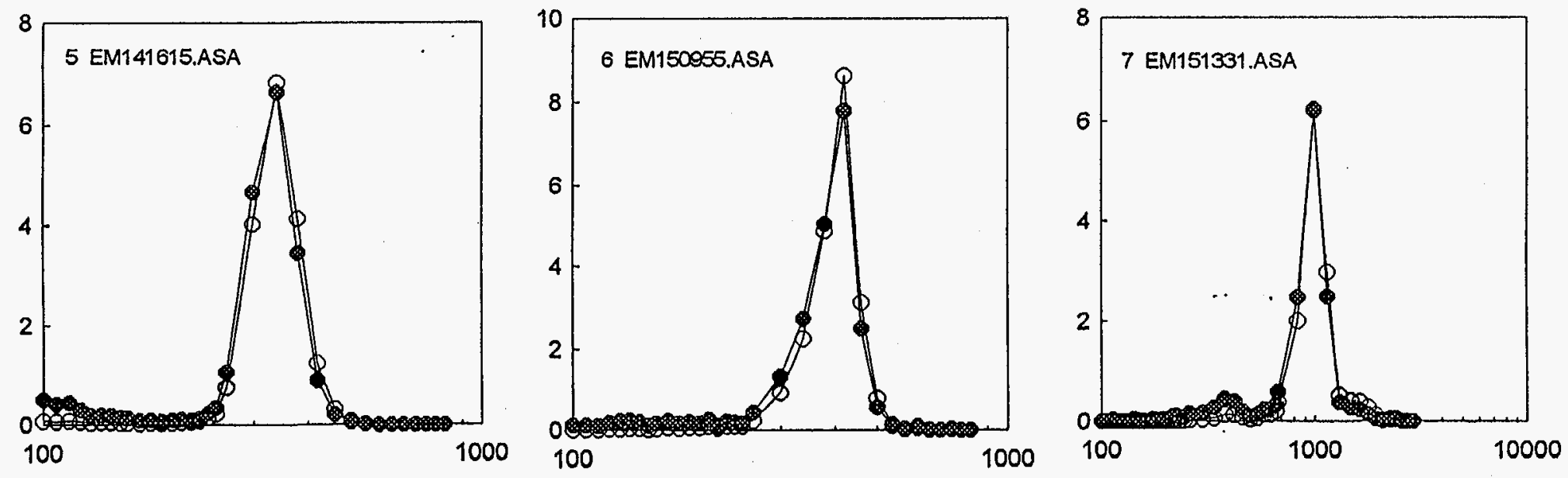

Figure 4. EML condensation Carnauba wax particle size distributions: number-weighted (dot) and attachment-rate-weighted (circle) measured with the ASASX. X-axis: diameter, nm: $y$ axis: $d X / X d \log D$, where $x=$ number concentration $\left(\mathrm{cm}^{-3}\right)$ or attachment rate $\left(\mathrm{h}^{-1}\right)$. 

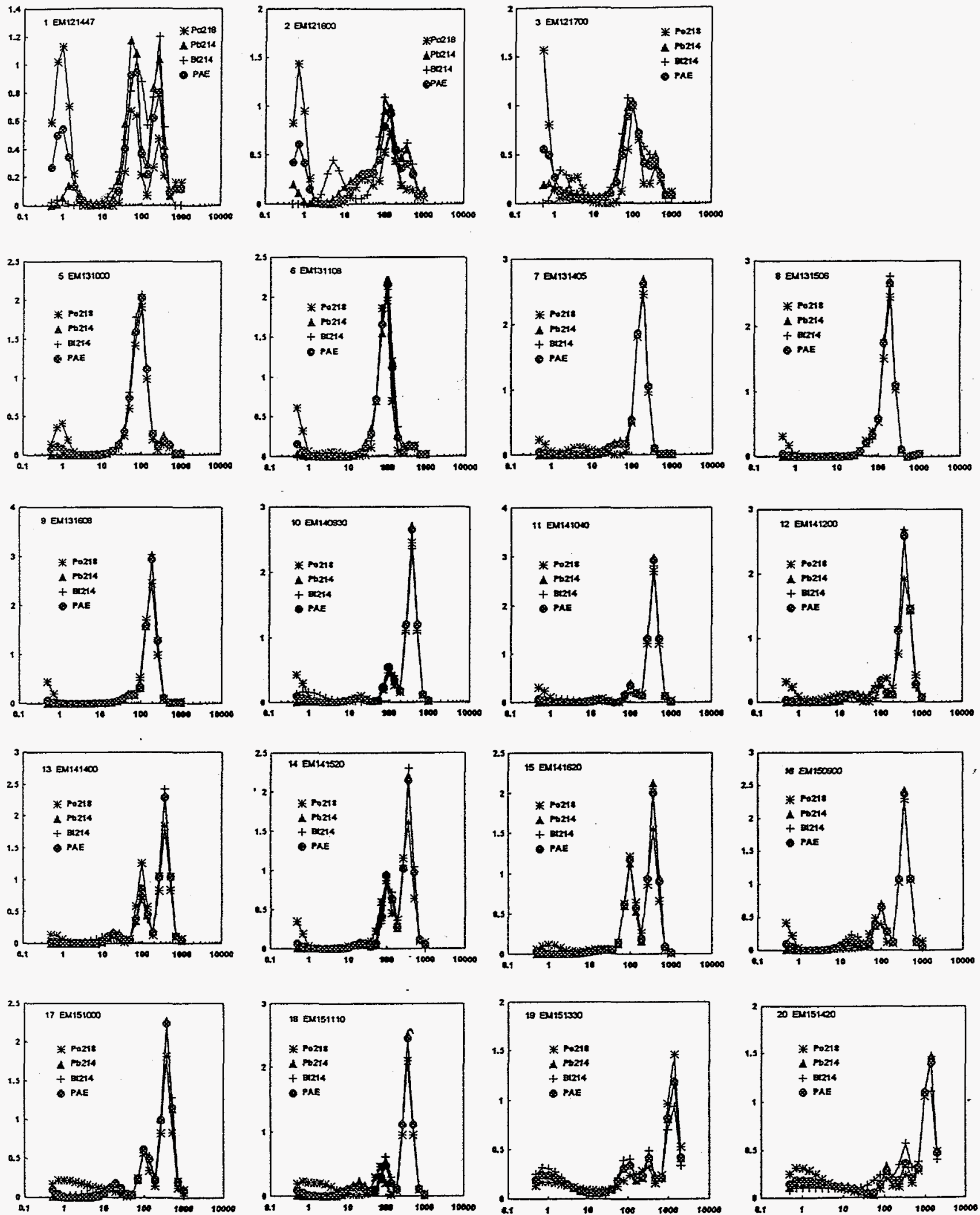

Figure 5. ${ }^{222} \mathrm{Rn}$ progeny size distributions - EML results. Absissa: particle diameter, $\mathrm{nm}$; ordinate: $\mathrm{dA} / \mathrm{A}$ dlog $\mathrm{D}$, where $\mathrm{A}=$ alpha activity in $\mathrm{Bq} \mathrm{m}{ }^{-3}$ for ${ }^{218} \mathrm{Po},{ }^{214} \mathrm{~Pb}$ and ${ }^{214} \mathrm{Bi}$, or in $\mathrm{nJ} \mathrm{m}^{-3}$ for PAEC, $\mathrm{D}=$ diameter, $\mathrm{nm}$. 

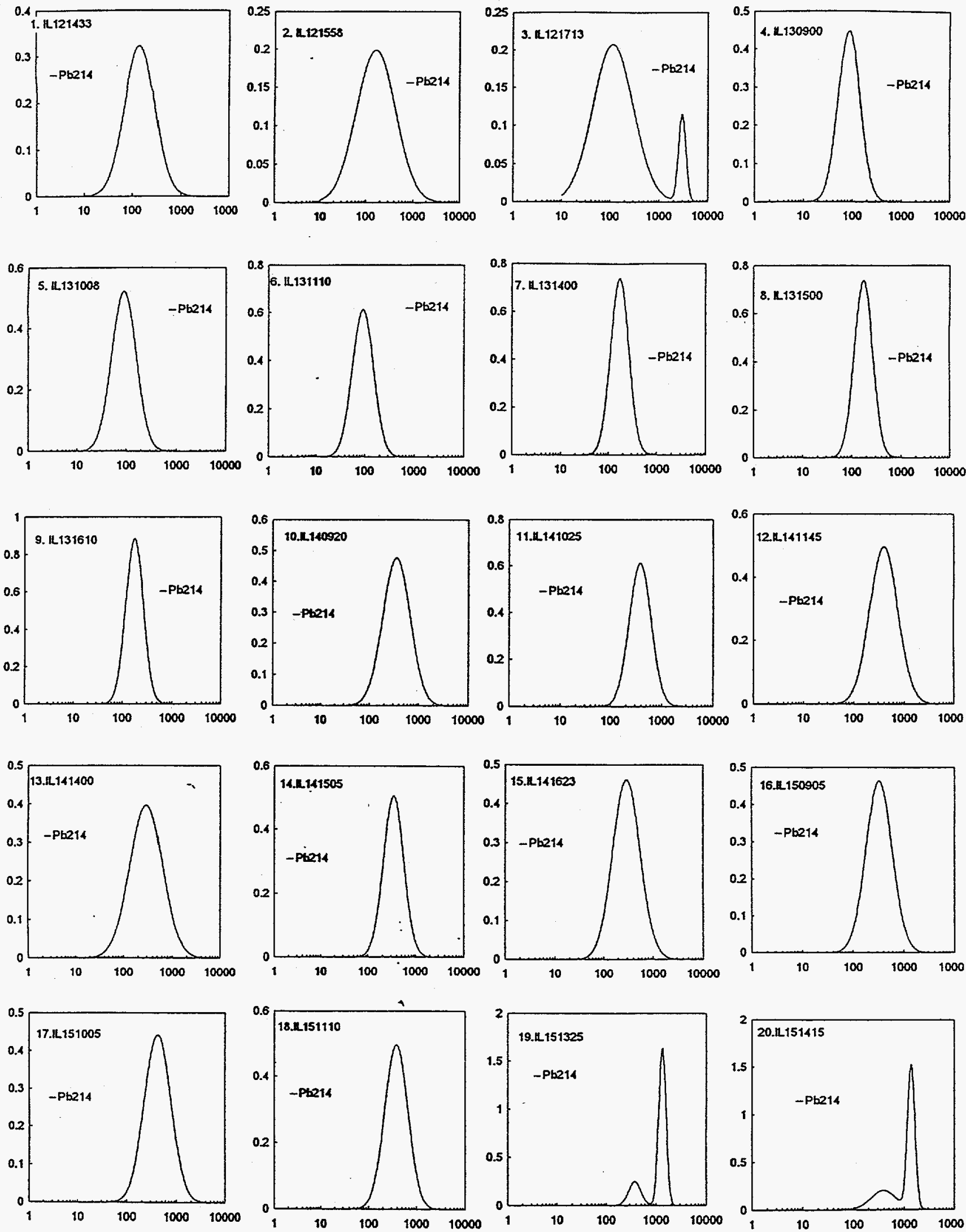

Figure 6. ${ }^{222} \mathrm{Rn}$ progeny size distributions $-\Pi$ results. Absissa: particle diameter, $\mathrm{nm}$; ordinate: $\mathrm{dA} / \mathrm{A}$ dlog $\mathrm{D}$, where $\mathrm{A}=$ alpha activity in $\mathrm{Bq} \mathrm{m}^{-3}$ for ${ }^{218} \mathrm{Po},{ }^{214} \mathrm{~Pb}$ and ${ }^{214} \mathrm{Bi}$, or in $\mathrm{nJ} \mathrm{m}^{-3}$ for $\mathrm{PAEC}, \mathrm{D}=$ diameter, $\mathrm{nm}$. 

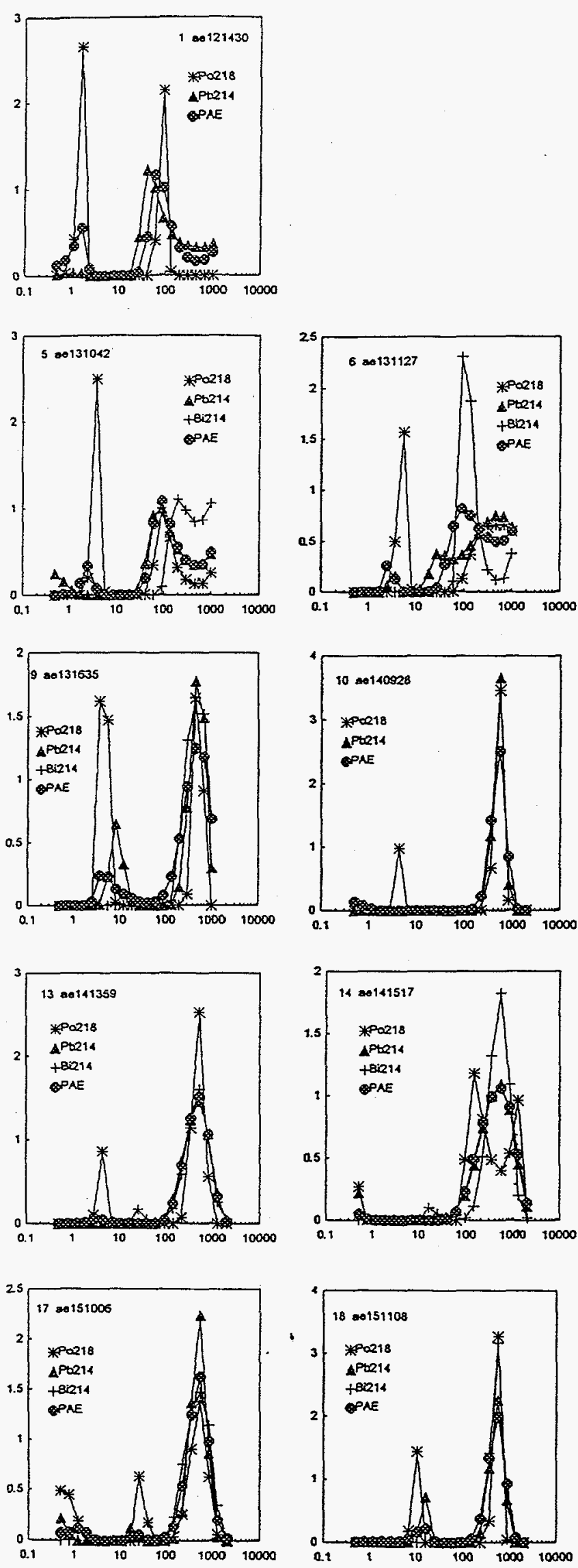
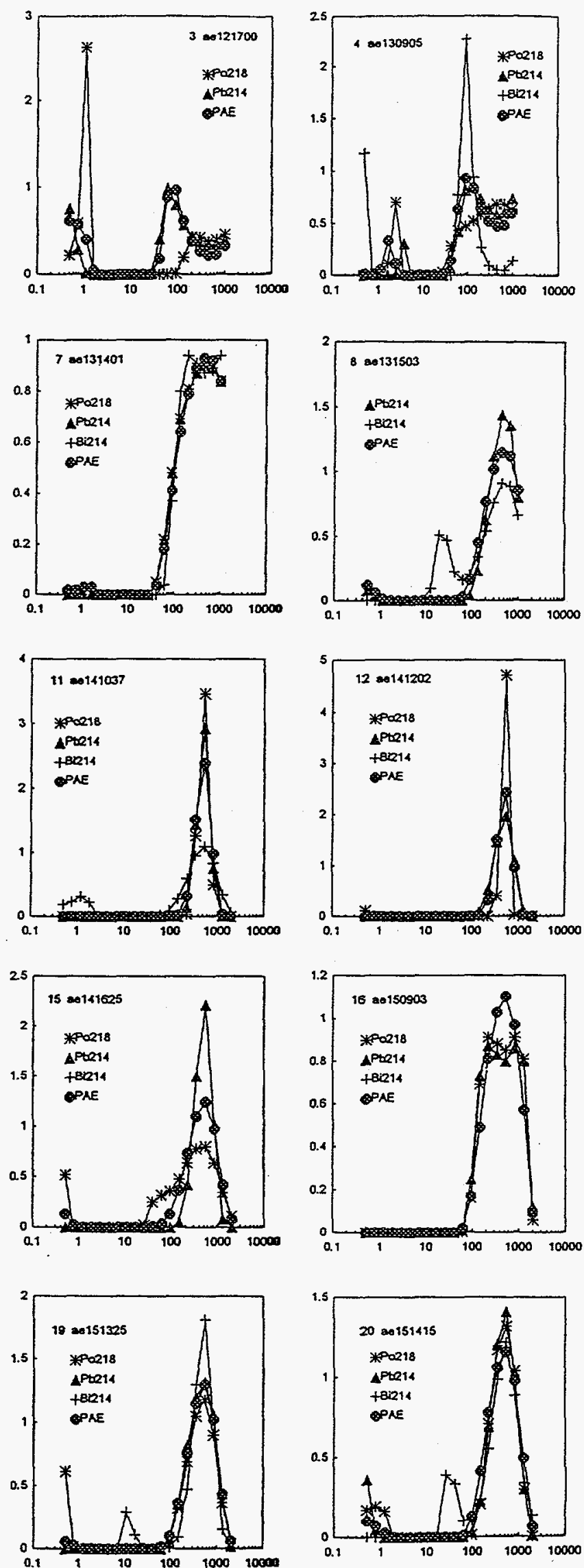

Figure 7. ${ }^{222} \mathrm{Rn}$ progeny size distributions - AEA results. Absissa: particle diameter, nm; ordinate: dA/A dlog $D$, where $\mathrm{A}=$ alpha activity in $\mathrm{Bq} \mathrm{m}^{-3}$ for ${ }^{218} \mathrm{Po},{ }^{214} \mathrm{~Pb}$ and ${ }^{214} \mathrm{Bi}$, or in $\mathrm{nJ} \mathrm{m} \mathrm{m}^{-3} \mathrm{PAEC}, \mathrm{D}=$ diameter, $\mathrm{nm}$. 

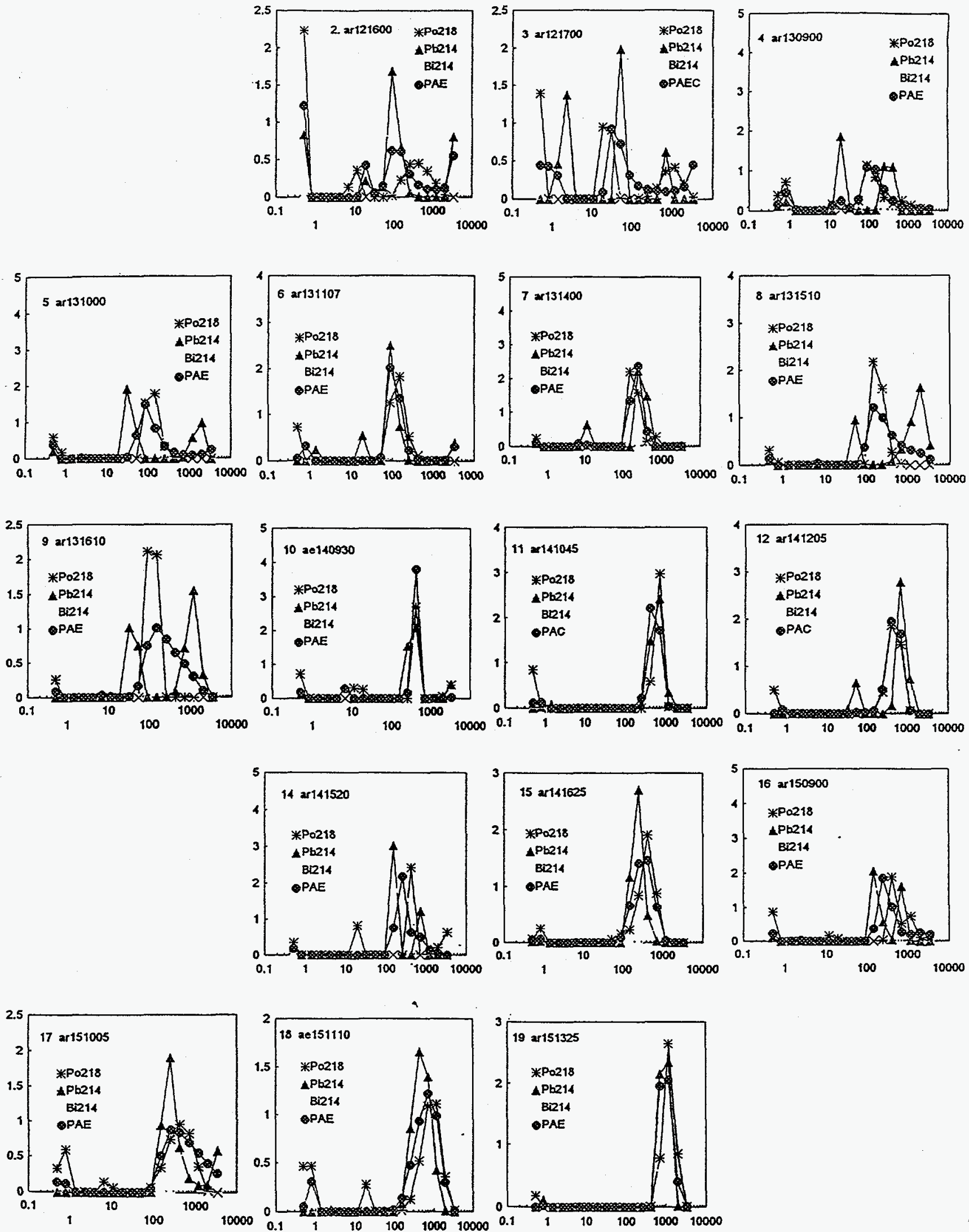

Figure 8. ${ }^{222} \mathrm{Rn}$ progeny size distributions - ARL results. Absissa: particle diameter, nm; ordinate: dAA dlog D, where $\mathrm{A}=$ alpha activity in $\mathrm{Bq} \mathrm{m} \mathrm{m}^{-3}$ for ${ }^{218} \mathrm{Po},{ }^{214} \mathrm{~Pb}$ and ${ }^{214} \mathrm{Bi}$, or in $\mathrm{nJ} \mathrm{m}^{-3}$ for $\mathrm{PAEC}, \mathrm{D}=$ diamerer, $\mathrm{nm}$. 


\section{PARTICIPANTS}

Dr. John Strong

AEA Technology (AEA)

Aerosol Science Center

551 Harwell, Oxfordshire

Tel. $\quad+44$ 1235-434152

OX 11 ORA United Kingdom

Fax +44 1235-434331

E-mail: John.strong@aea.orgn.uk

Dr. Stephen B. Solomon

Australian Radiation Laboratory (ARL)

Lower Plenty Road

Yallambie, Victoria 3085

Australia

Tel. $\quad+613-9433-2211$

Fax +61 3-9432-1835

E-mail: Stephen@smtp.orl.oz.au

Dr. August Reineking

Mr. Christian Zock

Isotopenlaboratorium fur biologische (IL)

und medizinische Forschung

der Universitat Gottingen

Burckhardtweg 2

3400 Gottingen

Federal Republic of Germany

Tel. $\quad+49$ 551-39-8113

Fax +49 551-39-8110

E-mail: areinek@gwdg.de

Dr. Robert Holub

Ms. Linda Killoran

Denver Research Center

Denver Federal Center, Bldg. 20

Denver, CO 80225 U.S.A.

Tel. + +1 303-236-0789

Fax +1 303-236-0828

E-mail: rholub@slate.mines.edu

Dr. Brian Fitzgerald

Mr. Olanrewaju Olaworin

Clarkson University

Department of Chemistry

Box 5810

Potsdam, NY 13699-5810 U.S.A.

Tel. $\quad+1315-268-6626$

Fax +1 315-268-6610

E-mail: fitzgebj@doaco.clarkson.edu 
Dr. Rainer Rolle

University of Salzburg

Institute of Physics and Biophysics

Hellbrunner Str. 34

Tel. $\quad+43662-8044-5709$

A-5020 Salzburg

Fax +43 662-8044-5704

Austria, Europe

Dr. Keng-Wu Tu

Dr. Earl O. Knutson

Dr. Alfred Cavallo

Environmental Measurements Laboratory (EML)

U.S. Department of Energy

Tel. $\quad+1$ 212-620-3361

201 Varick Street, 5th Floor

Fax +1 212-620-3600

New York, NY 10014-4811 U.S.A.

E-mail: acavallo@eml.doe.gov 